\title{
Rapid detection of polyhydroxyalkanoate- accumulating bacteria isolated from the environment by colony PCR
}

\author{
Der-Shyan Sheu, Yun-Ting Wang and Chia-Yin Lee
}

Graduate Institute of Agricultural Chemistry, National Taiwan University, 1, Sec. 4, Roosevelt Rd, Taipei 106, Taiwan
Author for correspondence: Chia-Yin Lee. Tel: +886223630231 ext. 2816. Fax: +88622366 0581 . e-mail:m477@ccms.ntu.edu.tw

Colony PCR and semi-nested PCR techniques were employed for screening polyhydroxyalkanoate (PHA) producers isolated from the environment. Three degenerate primers were designed based on multiple sequence alignment results and were used as PCR primers to detect PHA synthase genes. Optimized colony PCR conditions were achieved by adding $3 \%$ DMSO combined with 1 M betaine to the reaction mixture. The sensitivity limit of the colony PCR was $1 \times$ $10^{5}$ viable cells for Ralstonia eutropha. Nineteen PHA-positive bacteria were used to evaluate this PCR protocol; fifteen of the nineteen could be detected by colony PCR, and the other four could be detected by applying semi-nested PCR detection following colony PCR. In a preliminary screening project, 38 PHApositive strains were isolated from environmental samples by applying the PCR protocol, and their phenotype was further confirmed by Nile blue A staining assay. By combining the colony PCR and semi-nested PCR techniques, a rapid, reliable and highly accurate detection method has been developed for detecting PHA producers. This protocol is suitable for screening large numbers of environmental isolates. The PHA accumulation ability of well-separated colonies isolated from environmental samples can be directly validated by PCR with no further culturing or chromosomal DNA extraction procedures. In addition to its application to the screening of wild-type isolates, the individual PCR-amplified product is also suitable as a specific probe for PHA operon cloning. The results suggest that the application of this PCR protocol for rapid detection of PHA producers from the environment is plausible.

Keywords: colony PCR, semi-nested PCR, polyhydroxyalkanoates, PHA synthase, degenerate primers

\section{INTRODUCTION}

Polyhydroxyalkanoates (PHAs) function as carbon and energy reserves in prokaryotic cells (Anderson \& Dawes, 1990); they are accumulated by a wide range of bacteria when a carbon source is provided in excess and one essential growth nutrient is limited (Ramsay et al., 1990; Steinbüchel \& Schlegel, 1991). Since their physical characteristics are similar to those of petrochemical polyesters, such as polypropylene, PHAs have been studied intensively by academia and industry and are considered good candidates for biodegradable plastics and elastomers (Anderson \& Dawes, 1990; Poirier et al., 1995). The synthesis of PHAs requires the enzyme PHA

Abbreviation: PHA, polyhydroxyalkanoate. synthase (PhaC), which uses $\beta$-hydroxyacyl-coenzyme A substrates for polymerization. The production of such substrates can occur by a variety of pathways (Madison \& Huisman, 1999), including the simplest using the enzymes $\beta$-ketothiolase (encoded by $p h a A$ ) and acetoacetyl-CoA reductase (encoded by $p h a B$ ), $\beta$-oxidation (Page \& Manchak, 1995), and a fatty acid de novo synthesis pathway (Rehm et al., 1998). So far, more than 20 kinds of PHA synthesis operons have been cloned and analysed from a variety of bacteria; the results reveal that the proteins required for PHA biosynthesis pathways have diverged considerably (Madison \& Huisman, 1999). Nevertheless, PHA synthase is a crucial enzyme in all PHA synthesis pathways (Anderson \& Dawes, 1990; Madison \& Huisman, 1999; Rehm \& Steinbüchel, 1999). The PHA synthases can be broadly categorized into three different types based on their primary amino acid 
sequences and in vivo substrate specificities (Rehm \& Steinbüchel, 1999). Type I PHA synthases (Ralstonia eutropha) are preferentially active towards coenzyme A thioesters of various short-chain-length 3-hydroxyalkanoates comprising three to five carbon atoms. Type II PHA synthases (Pseudomonas aeruginosa) are preferentially active towards coenzyme A thioesters of various medium-chain-length 3-hydroxyalkanoates comprising at least five carbon atoms. Type III PHA synthases (Chromatium vinosum) comprise enzymes consisting of two different types of subunits, the PhaC subunit and the PhaE subunit. These PHA synthases prefer coenzyme A thioesters of short-chain-length 3hydroxyalkanoates.

There are many phenotypic detection methods for detecting intracellular PHA granules which are applied to the screening of PHA producers, including Sudan Black staining (Schlegel et al., 1970) and Nile blue A staining (Ostle \& Holt, 1982), which result in dark blue or fluorescent granules. Although these methods are quite sensitive, it is rather time-consuming and labourintensive work to screen a large number of environmental isolates. Alternative staining methods have recently been developed for directly staining colonies (Kranz et al., 1997) or growing bacteria on plates containing Nile blue A or Nile red (Spiekermann et al., 1999), resulting in fluorescent colonies that can be visualized by UV illumination. These colony-staining methods are suitable for screening large numbers of strains. However, appropriate carbon sources should be used, and a long culture time $(3 \mathrm{~d})$ is required for PHA granule accumulation. In addition, these methods cannot distinguish between bacteria that accumulate PHA granules and those that accumulate lipid compounds.

In this study, a genotypic detection method, which circumvents the major drawbacks inherent in phenotypic detection methods described above, was devised.

\section{METHODS}

Bacterial strains and media. Nineteen PHA-positive bacterial strains [Ralstonia eutropha H16 ATCC 17699 (formerly known as Alcaligenes eutrophus), Alcaligenes bydrogenophilus ATCC 33178, A. latus ATCC 15440, Comamonas (Delftia) acidovorans ATCC 15668, Hydrogenophaga palleronii ATCC 17724, H. pseudoflava ATCC 33668, Pseudomonas alcaligenes ATCC 14909, P. aureofaciens ATCC 13986, P. citronellolis ATCC 13674, P. fluorescens ATCC 12983, P. (Burkholderia) glathei ATCC 29195, P. mendocina ATCC 25411, P. oleovorans ATCC 8062, P. pseudoalcaligenes ATCC 17440, P. putida ATCC 12633, Sphaerotilus natans ATCC 15291, Azotobacter chroococcum ATCC 9043, A. vinelandii ATCC 478 and Bacillus megaterium CCRC 11595] and one PHA-negative bacterium, Escherichia coli XL-1 Blue (Bullock et al., 1987) were used. Mineral salt medium (MSM) pH 7·0 (Ramsay et al., 1990) was used for the isolation of bacterial strains from environmental samples. Carbohydrates and mineral salt solutions were sterilized separately, and combined prior to culturing.

Nucleotide sequence analysis. The nucleotide sequences of 13 PHA synthase $(p h a C)$ genes were collected for sequence analysis, derived from the following Gram-negative bacteria:
Acinetobacter sp. (Schembri et al., 1994), Aeromonas caviae (Fukui \& Doi, 1997), Ralstonia eutropha (formerly known as Alcaligenes eutrophus) (Peoples \& Sinskey, 1989), Alcaligenes sp. (GenBank accession no. U78047), Methylobacterium extorquens (Valentin \& Steinbüchel, 1993), Paracoccus denitrificans (Ueda et al., 1996), Pseudomonas aeruginosa (Timm $\&$ Steinbüchel, 1992) (containing two phaC genes), P. oleovorans (Huisman et al., 1991) (containing two phaC genes), Rhizobium etli (Cevallos et al., 1996), Rhizobium meliloti (Tombolini et al., 1995) and Zoogloea ramigera (GenBank accession no. U66242). Multiple sequence alignment was achieved by employing the SeqWeb software allowing a GapWeight of 10 and a GapLengthWeight of 5.

Synthetic oligonucleotide primers. Three degenerate primers (all 26-mers) were designed and synthesized according to the multiple sequence alignment results. The sequences were $5^{\prime}-$ ATCAACAA(GGG/A)T(TT/A)CTAC(AA/G)TC(CC/T)$\mathrm{T}(\mathrm{CC} / \mathrm{G}) \mathrm{GACCT}-3^{\prime}$ (designated phaCF1, corresponding to nt 741-766 of $R$. eutropha phaC), 5'-GT(CCC/GG)TTC(GGG/AA)T(GGG/CC) (AAA/GG)T(CC/G)(TT/A)(CCC/GG)CTGGCGCAACCC-3' (designated phaCF2, corresponding to nt 846-871 of R. eutropha phaC) and 5'-AGGTAGTTGT(TT/C)GAC(CCC/GG)(AAA/CC)(AAA/CC)(GGG/A)TAG (TTT/G)TCCA-3' (designated phaCR4, corresponding to nt 1237-1212 of R. eutropha phaC).

Colony PCR. The optimized colony PCR reaction mixture contained $1 \times \mathrm{PCR}$ amplification buffer $\left[20 \mathrm{mM}\left(\mathrm{NH}_{4}\right)_{2} \mathrm{SO}_{4}\right.$, $72.5 \mathrm{mM}$ Tris/HCl, 0.1\% Tween 20, pH 9.0], $2.5 \mathrm{mM} \mathrm{MgCl}_{2}$, $200 \mu \mathrm{M}$ each deoxynucleotide triphosphate, $2 \cdot 5 \mu \mathrm{M}$ each primer, $1.25 \mathrm{U}$ Supertherm DNA polymerase (LPI) in $50 \mu \mathrm{l}$ PCR reaction mixture. A final concentration of $100 \mu \mathrm{g} \mathrm{ml} l^{-1}$ of acetylated BSA (New England BioLabs), 3\% dimethyl sulfoxide (DMSO) (Sigma) and $1 \mathrm{M}$ betaine (Sigma) as PCR additives were also added to the reaction mixture. Colonies approximately $1 \mathrm{~mm}$ in diameter were picked up with a sterilized toothpick and directly transferred to the PCR tube as DNA templates. The thermal cycle programme, run on a GeneAmp PCR system 9700 (Perkin Elmer) consisted of one cycle of $94^{\circ} \mathrm{C}$ for $10 \mathrm{~min}, 51^{\circ} \mathrm{C}$ for $2 \mathrm{~min}, 72^{\circ} \mathrm{C}$ for $2 \mathrm{~min}$, and 35 cycles of $94^{\circ} \mathrm{C}$ for $20 \mathrm{~s}, 57^{\circ} \mathrm{C}$ for $45 \mathrm{~s}$ (decreased by $1 \mathrm{~s}$ per cycle), $72{ }^{\circ} \mathrm{C}$ for $1 \mathrm{~min}$, and then incubation at $72^{\circ} \mathrm{C}$ for $5 \mathrm{~min}$, and a final incubation at $4{ }^{\circ} \mathrm{C}$.

Sensitivity of colony PCR. Tenfold serial dilutions of $R$. eutropha overnight cultures were prepared in nutrient broth. Aliquots of each dilution were subjected to plate counting to determine bacterial cell concentration. Other aliquots of each dilution were centrifuged, and the cell pellet was washed once with sterilized deionized water and then used as DNA template for PCR.

Detection of PCR products. PCR-amplified DNA fragments were observed by agarose gel electrophoresis in $1.3 \%$ agarose gels (FMC). Ten microlitres of each amplification mixture and the molecular mass marker (HaeIII digest of $\phi$ X174 DNA) were subjected to agarose gel electrophoresis and ethidium bromide staining. The amplified DNA fragments were visualized by UV illumination.

Southern hybridization. To confirm the amplified DNA fragment, $10 \mu \mathrm{l}$ of colony PCR products was subjected to $1.3 \%$ agarose gel electrophoresis and then transferred to a Hybond-N + membrane (Amersham) by alkaline Southern transfer (Reed \& Mann, 1985). An internal oligonucleotide probe, phaCF2, was labelled with $\left[\gamma^{-32} \mathrm{P}\right] \mathrm{ATP}$ by $5^{\prime}$-end labelling with T4 polynucleotide kinase (New England BioLabs) as a probe $\left(1.5 \mathrm{ng} \mathrm{ml}^{-1}\right)$. The membranes were air-dried and hybridized at $38^{\circ} \mathrm{C}$ overnight in $1 \times$ SSC buffer containing 
$1 \%$ SDS, $1 \%$ casein (Merck), $0 \cdot 5 \mathrm{mg} \mathrm{ml}^{-1}$ of denatured herring sperm DNA (Boehringer Mannheim) and $50 \%$ (v/v) deionized formamide (Clontech). At low stringency, the buffer and hybridization temperature were the same as those above except for the lack of formamide. After hybridization, the membranes were rinsed with $2 \times \mathrm{SSC}$ and $2 \times \mathrm{SSC} / 0 \cdot 1 \%$ SDS at $38{ }^{\circ} \mathrm{C}$, followed by $0.5 \times \mathrm{SSC} / 0 \cdot 1 \%$ SDS at $25^{\circ} \mathrm{C}$. Then the membranes were autoradiographed with X-ray film (Fuji) and exposed at $-70{ }^{\circ} \mathrm{C}$ for an appropriate length of time.

Semi-nested PCR. Semi-nested PCR was done with the primers phaCF2 and phaCR4, with a predicted product of $406 \mathrm{bp}$, to further confirm the colony PCR results. For positive products, $1 \mu \mathrm{l}$ of 100 -fold-diluted colony PCR products was subjected to semi-nested PCR. For negative products, $1 \mu \mathrm{l}$ of undiluted colony PCR products was directly supplied as DNA templates for semi-nested PCR. The $50 \mu \mathrm{l}$ PCR mixture contained $1 \times$ PCR amplification buffer, $1.5 \mathrm{mM} \mathrm{MgCl}_{2}, 200 \mu \mathrm{M}$ each deoxynucleotide triphosphate, $2 \mu \mathrm{M}$ each primer, $2 \%$ DMSO and $0.5 \mathrm{U}$ Supertherm DNA polymerase. The thermal cycle programme, run on a GeneAmp PCR system 9700 (Perkin Elmer), was $94^{\circ} \mathrm{C}$ for $5 \mathrm{~min}$ (initial denaturation), 25 cycles of $94{ }^{\circ} \mathrm{C}$ for $15 \mathrm{~s}, 57^{\circ} \mathrm{C}$ for $15 \mathrm{~s}, 72^{\circ} \mathrm{C}$ for $30 \mathrm{~s}$, and then incubation at $72^{\circ} \mathrm{C}$ for an additional $5 \mathrm{~min}$, with final incubation at $4{ }^{\circ} \mathrm{C}$.

Isolation and screening of environmental strains. The screening procedure for PHA producers from the environment was modified from Gomez et al. (1996). Serial dilutions of active sludge were prepared in MSM. Aliquots of the dilution series were spread onto MSM plates containing $1 \%(\mathrm{w} / \mathrm{v})$ sucrose (Sigma), 1.5\% (w/v) sodium gluconate (Wako), $1 \%$ $(\mathrm{w} / \mathrm{v})$ glycerol (Sigma) or $0.1 \%(\mathrm{w} / \mathrm{v})$ sodium octanoate (Wako) as carbon sources and were cultured at $30^{\circ} \mathrm{C}$ overnight. The grown colonies were individually streaked onto MSM plates containing appropriate carbon sources to obtain well-separated single colonies. The PHA producer candidates were directly screened by colony PCR and seminested PCR from these well-separated colonies.

Nile blue A staining. PHA-positive strains identified by PCR were cultured in $50 \mathrm{ml}$ MSM containing an appropriate carbon source at $30^{\circ} \mathrm{C}$ with reciprocal shaking at 150 r.p.m. for $3 \mathrm{~d}$. The bacterial cells were stained with Nile blue A and observed as described by Ostle \& Holt (1982). The fluorescence microscope used was an Olympus AX 70; the excitation filter, barrier filter and dichroic mirror sets were BP450-480, BA515 and DM500, respectively. The staining results were photographed in colour on Kodak Kodacolor print film (400 ASA).

\section{RESULTS}

\section{DNA sequence alignment}

Thirteen PHA synthase gene sequences from Gramnegative bacteria (see Methods) were aligned. The

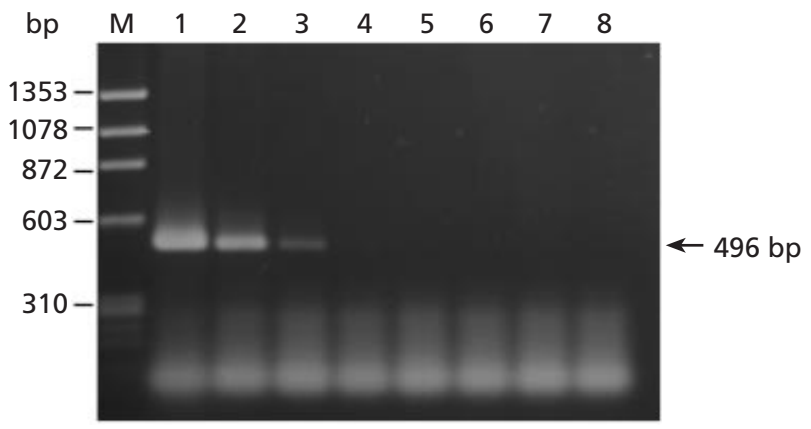

Fig. 2. Detection limit of $R$. eutropha by colony PCR with primer pair phaCF1-phaCR4 and $R$. eutropha cells as the DNA template. Lane $\mathrm{M}$, molecular size marker ( $\phi$ X174 DNA/HaellI); lane $1,1.1 \times 10^{8}$ c.f.u.; lane $2,1.1 \times 10^{7}$ c.f.u.; lane $3,1.1 \times 10^{6}$ c.f.u.; lane $4,1.1 \times 10^{5}$ c.f.u.; lane $5,1.1 \times 10^{4}$ c.f.u.; lane 6 , $1 \cdot 1 \times 10^{3}$ c.f.u.; lane $7,1 \cdot 1 \times 10^{2}$ c.f.u.; lane $8,1 \cdot 1 \times 10$ c.f.u.

PILEUP results showed that there were seven highly conserved regions among the 13 sequences. The corresponding positions of these conserved regions are depicted on the phaC of R. eutropha in Fig. 1. Based on the F1, F2 and R4 conserved region sequences, three degenerate primers, phaCF1, phaCF2 and phaCR4, were designed for PCR amplification and Southern hybridization (see Methods).

\section{Optimization of colony PCR}

To establish a rapid screening protocol, a colony PCR approach with degenerate primers, phaCF1 and phaCR4, was employed. The predicted product, amplified from $R$. eutropha, was $496 \mathrm{bp}$. In each PCR experiment, $50 \mu \mathrm{l}$ of $R$. eutropha overnight culture directly served as the DNA template following centrifuging and washing once with sterilized deionized water. In the preliminary test, no PCR product was amplified without the help of PCR additives (data not shown). However, a very specific DNA fragment, $\sim 500 \mathrm{bp}$, was amplified when a final concentration of $2 \%$ DMSO was added to the PCR mixture. Moreover, the PCR product was enriched ( $\sim 1.9$-fold $)$ when DMSO was replaced by $1 \mathrm{M}$ betaine. Finally, the optimized condition was achieved by combining $3 \%$ DMSO and $1 \mathrm{M}$ betaine in the PCR mixture to obtain an approximately $2 \cdot 2$-fold enrichment (data not shown) as compared to the result obtained, when only DMSO was

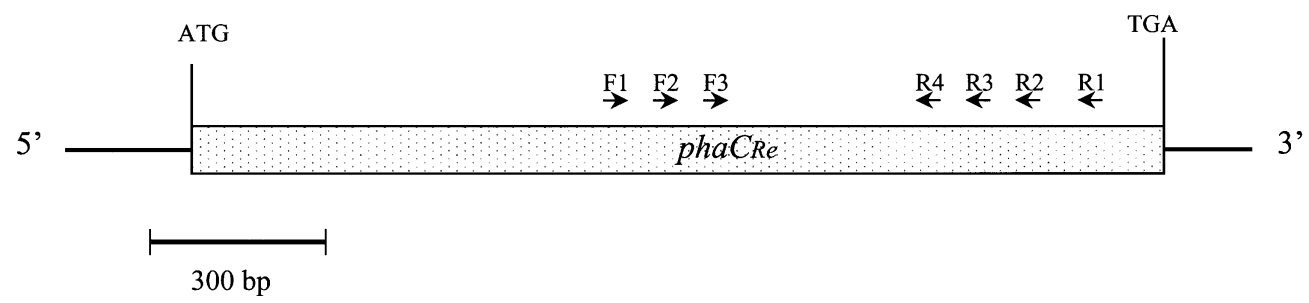

Fig. 1. Positions of primers on the phaC gene of $R$. eutropha. F1, phaCF1; F2, phaCF2; F3, phaCF3; R4, phaCR4; R3, phaCR3; R2, phaCR2; R1, phaCR1. 
(a)

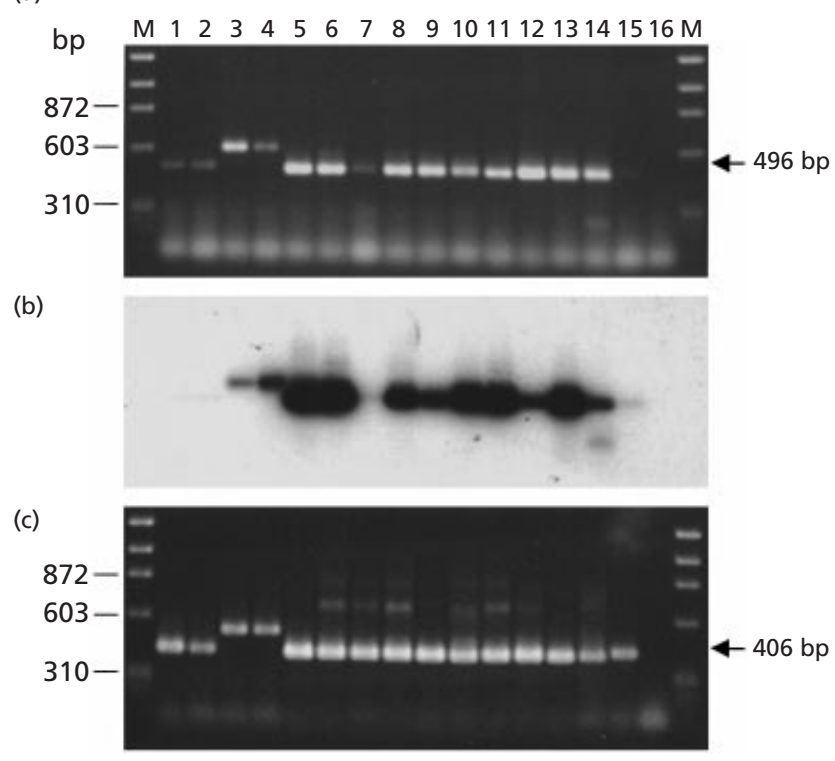

Fig. 3. Results of colony $P C R$ amplification with primer pair phaCF1-phaCR4 among PHA-positive strains. (a) Agarose gel electrophoresis of colony PCR products. (b) Southern hybridization of the products probed with ${ }^{32} \mathrm{P}$-labelled phaCF2. (c) Confirmation by semi-nested PCR. Lanes: M, molecular size marker ( $\phi$ X174 DNA/HaellI); 1, R. eutropha, 2, A. hydrogenophilus; 3, A. latus; 4, C. acidovorans; 5, H. palleronii; 6, $P$. alcaligenes; 7, $P$. aureofaciens; $8, P$. citronellolis; $9, P$. fluorescens; $10, P$. glathei; 11, $P$. mendocina; $12, P$. oleovorans; $13, P$. pseudalcaligenes; $14, P$. putida; $15, S$. natans; 16, E. coli $\mathrm{XL}-1$ Blue (negative control).

added. The results clearly demonstrated that a colonyPCR-based approach with these degenerate primers could specifically amplify the DNA fragment from the PHA synthase gene without additional chromosomal DNA extraction procedures. The detailed PCR thermal program and reaction mixture composition are described in Methods.

\section{Sensitivity of colony PCR}

A dilution series of R. eutropha cells was prepared as DNA templates for testing the sensitivity of the colony PCR. The detection limit of the colony PCR was approximately $1 \times 10^{5}$ viable cells (Fig. 2 ). On the basis of the results, colonies approximately $1 \mathrm{~mm}$ in diameter, containing $\sim 1 \times 10^{7}$ viable cells, were picked up as DNA templates for colony PCR in the following experiments.

\section{Evaluation of the detection efficiency of colony PCR}

Nineteen PHA-positive bacteria, 18 Gram-negative and one Gram-positive, as well as one PHA-negative strain (E. coli XL-1 Blue) were used to evaluate the detection efficiency of the colony PCR. Among these bacterial strains, 15 were detected by colony PCR and five (E. coli XL-1 Blue, H. pseudoflava, A. chroococcum, A. vinelandii and B. megaterium) were not detected. The 15

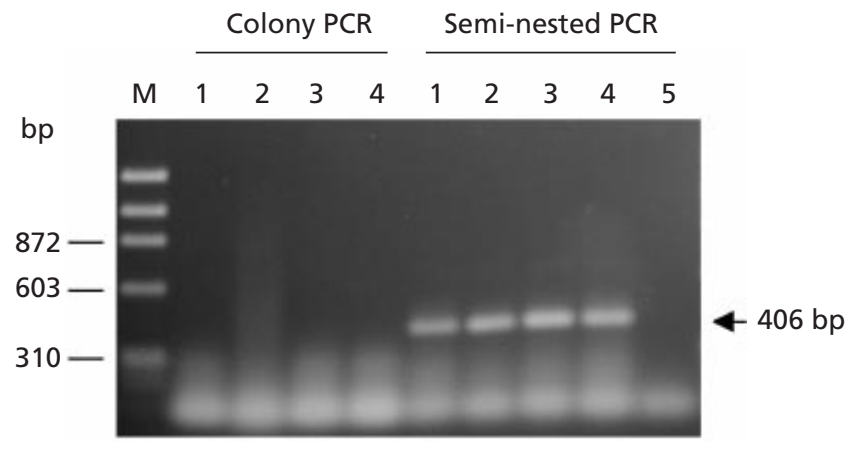

Fig. 4. Analysis of colony-PCR-negative products and their confirmation by semi-nested PCR. Primer-pair phaCF1-phaCR4 was used in colony PCR and phaCF2-phaCR4 was used in semi-nested PCR. Lanes: $\mathrm{M}$, molecular size marker ( $\phi \mathrm{X} 174$ DNA/HaellI); $1, H$. pseudoflava; 2, A. chroococcum; $3, A$. vinelandii; 4, B. megaterium; 5, E. coli XL-1 Blue (negative control).

detected strains belonged to six genera: Alcaligenes, Comamonas, Hydrogenophaga, Pseudomonas, Ralstonia and Sphaerotilus. Furthermore, two types of PHA synthases, type I (e.g. PHA synthase of R. eutropha) and type II (e.g. PHA synthase of P. oleovorans), were simultaneously detected by the same primer pair. When the semi-nested PCR technique was combined with colony PCR (Figs 3 and 4) all 19 PHA-positive strains were detected; the negative control E. coli XL-1 Blue did not produce a signal following semi-nested PCR (Fig. 4, lane 5). The detection experiments were repeated three times with the same results, confirming reproducibility. The size of the PCR products consistently matched the predicted results except for A. latus and C. acidovorans, from which larger fragments were amplified (Fig. 3, lanes 3 and 4).

\section{Confirmation of colony PCR products by Southern hybridization and semi-nested PCR}

Southern hybridization was carried out for further confirmation of the identity of the PCR products with a degenerate probe, phaCF2, targeting the internal regions (Fig. 1). Most of the colony-PCR-positive products were detected at high stringency except for four products amplified from R. eutropha (Fig. 3, lane 1), A. hydrogenophilus (Fig. 3, lane 2), P. aureofaciens (Fig. 3, lane 7) and $S$. natans (Fig. 3, lane 15). At low stringency (without formamide), the above four products possessed obvious signals (Fig. 5), except that $S$. natans needed a longer exposure time. No hybridization signals were observed among the colony-PCR-negative products even at low stringency (data not shown). The results suggested that the phaCF2 probe is capable of being a universal probe to confirm the identity of the colony PCR products. However, the sensitivity was not satisfactory, perhaps due to the highly degenerate probe used. Therefore, a very sensitive method, semi-nested PCR (Zhang et al., 1994), employing the primer pair phaCF2-phaCR4, was developed as a fast method for 
(a)

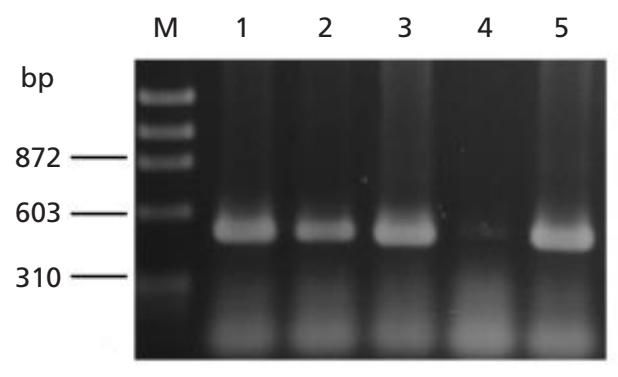

(b)

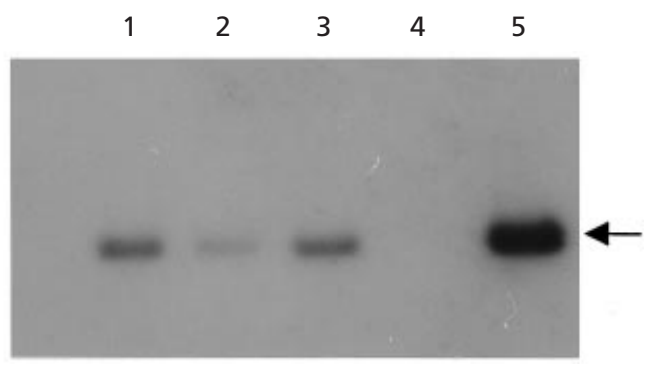

Fig. 5. Southern hybridization of phaCF1-phaCR4 colony PCR products under low-stringency hybridization conditions. (a) Agarose gel electrophoresis. (b) Southern hybridization analysis with low hybridization stringency. Lanes $M$, molecular size marker ( $\phi$ X174 DNA/HaellI); 1, Ralstonia eutropha; 2, Alcaligenes hydrogenophilus; 3, Pseudomonas aureofaciens; 4, Sphaerotilus natans; 5, Hydrogenophaga palleronii.
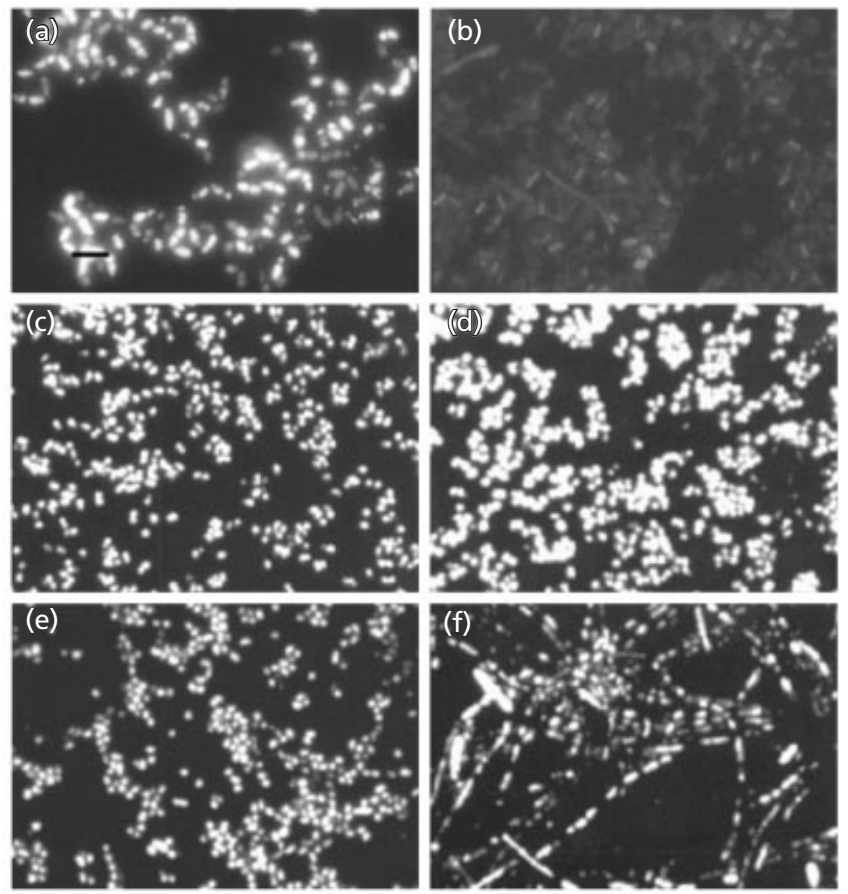

Fig. 6. Fluorescence microscopy of Nile-blue-A-stained cells grown in nitrogen-limited medium for $3 \mathrm{~d}$. (a) Positive control, Hydrogenophaga palleronii. (b) Negative control, E. coli XL-1 Blue. (c), (d), (e) and (f) are environmental isolates CS5, GS28, GG45 and GG47, respectively. Bar, $5 \mu \mathrm{m}$.

further confirmation of the PCR products. From the results in Fig. 3, DNA fragments of the predicted size (406 bp) could all be amplified from colony PCR products by semi-nested PCR, even from the four PHApositive strains that did not produce a colony PCR product (Fig. 4). This result suggested that colony-PCRnegative products still contain trace amounts of specifically amplified DNA fragments, which could not be detected by ethidium bromide staining. By semi-nested PCR, the unobserved signal was amplified and detected again. Moreover, the Gram-positive and PHA-positive
B. megaterium strain could also be detected by seminested PCR following colony PCR (Fig. 4, lane 4). This suggested that the primers derived from $p h a C$ genes of Gram-negative bacteria may also be efficient for the detection of Gram-positive PHA producers. In the 19 semi-nested PCR products, two larger-than-predicted PCR products were amplified from A. latus and C. acidovorans (Fig. 3, lanes 3 and 4). This phenomenon is the same as that seen with colony PCR.

\section{Screening of PHA producers from the environment by colony PCR and semi-nested PCR}

A total of 38 PHA-positive strains was isolated from environmental samples by colony PCR and semi-nested PCR. Thirty of these isolates were Gram-negative, five were Gram-positive and three were Gram-variable. The results suggest that the degenerate primers were not only specific for $p h a C$ genes from Gram-negative but also for those from Gram-positive bacteria. The phenotypes of PHA-genotype-positive isolates were further confirmed by Nile blue A staining (Fig. 6). The staining assay revealed that 33 of the 38 genotype-positive isolates possessed significant PHA accumulation ability; the remaining five strains were not confirmed by Nile blue A staining.

\section{DISCUSSION}

$\mathrm{G}+\mathrm{C}$ content analysis of 13 PHA synthase ( $p h a C$ ) genes, all derived from Gram-negative bacteria, revealed that these genes possess relatively high $\mathrm{G}+\mathrm{C}$ contents, at approximately $61-68 \mathrm{~mol} \%$, except for $p h a C$ from Acinetobacter sp. $(38.8 \%)$. Part of the PCR amplicon amplified from $R$. eutropha even possesses up to 89 $\mathrm{mol} \% \mathrm{G}+\mathrm{C}$ (50 GC bases in a 56-base length). DNA templates with a high $\mathrm{G}+\mathrm{C}$ content usually hamper PCR amplification; the reagents formamide, glycerol, DMSO and betaine often serve as PCR additives to overcome these problems (Dieffenbach \& Dveksler, 1995; Henke et al., 1997). In this study, different concentrations of the above PCR additives were tried; however, only DMSO and betaine were helpful (data 
not shown) in amplifying a correct-sized DNA fragment from the phaC gene. Six thermostable DNA polymerases, Taq (Promega), TaKaRa Taq (TaKaRa), KlenTaq1 (Ab Peptides), DyNAzyme II DNA polymerase (Finnzymes), Vent ${ }_{\mathrm{R}}$ DNA polymerase (New England BioLabs) and Supertherm DNA polymerase (LPI), were also evaluated for their ability to amplify the high-G $+\mathrm{C}$ template in the process of colony PCR detection. The Supertherm DNA polymerase showed the best detection results. Regarding the detection limits, the sensitivity of colony PCR is low, which might be due to the high degeneracy of the primers as well as to the low purity of chromosomal DNA. However, by omitting the tedious chromosomal DNA extraction procedures, a large number of samples can rapidly be screened at the same time. Another merit of PCR detection is that the PHA producers can be detected when grown on nutrient medium and no PHA granules have accumulated.

The sizes of products obtained by colony PCR and seminested PCR were consistent with the predicted results except those of A. latus and C. acidovorans, for which sizes were larger than predicted (Fig. 3, lanes 3 and 4). Recently, the phaC genes of A. latus (Choi et al., 1998) and C. acidovorans (Sudesh et al., 1998) have been cloned and sequenced. Aligning the primer positions, the corresponding products, 593 and $518 \mathrm{bp}$, would be amplified from A. latus by primer pairs phaCF1-phaR4 and phaCF2-phaCR4, respectively. In C. acidovorans, the corresponding products were 621 and $555 \mathrm{bp}$ by the above primer pairs. The predictive products were larger than the former; however, they obviously matched our agarose gel analysis results.

Thirty-eight PHA-positive strains isolated from the environment by PCR were further confirmed by Nile blue A staining assay. Among these isolates, 87\% (33/38) possessed significant PHA accumulation ability, which strongly supports the accuracy of the genotype screening results. However, there are still five isolates $(13 \%)$ for which no PHA granules were detected by Nile blue A staining. This outcome may be due to an inappropriate carbon source used in the culture medium or to a low yield of PHA granule accumulation resulting in negative detection by Nile blue A staining. These results also reflected the possibility that there may be some bacterial isolates that harbour a non-functional PHA synthase gene. The PHA-positive strains identified included five Gram-positive and five Gram-variable strains. This suggested that the colony PCR protocol is also applicable for detecting Gram-positive PHA producers.

It is often difficult to carry out gene cloning of PHA operons due to the lack of a universal probe. The degenerate primers used in this study were capable of amplifying a partial DNA fragment of $p h a C$ from all 19 reference strains, including strains from which pha operons have not yet been cloned (e.g. A. vinelandii and A. chroococcum). In addition, these individual PCR products are very suitable for use as specific probes for genomic library screening. The PCR protocol can also be regarded as a universal method to prepare a PHAsynthase-specific probe from individual strains for gene cloning. Alternatively, genomic library screening can also be rapidly achieved by using colony PCR directly. The colony PCR technique proposed in this study will significantly accelerate the discovery of new PHA operons.

\section{ACKNOWLEDGEMENTS}

This study was partially supported by grant 88 -EC-2-A-170235 from the Development Center for Biotechnology, Taipei, Taiwan. We wish to thank Associate Professor I-Ceng Tseng (Department of Biology, National Cheng Kung University, Tainan, Taiwan) for kindly providing active-sludge samples and Professor Liang-Ping Lin (Department of Agricultural Chemistry, National Taiwan University, Taipei, Taiwan) for providing strains of Azotobacter vinelandii and Azotobacter chroococcum.

\section{REFERENCES}

Anderson, A. J. \& Dawes, E. A. (1990). Occurrence, metabolism, metabolic role, and industrial uses of bacterial polyhydroxyalkanoates. Microbiol Rev 54, 450-472.

Bullock, W. O., Fernandez, J. M. \& Short, J. M. (1987). XL-1 Blue: high efficiency plasmid transforming recA Escherichia coli strain with $\beta$-galactosidase selection. Biotechniques 5, 376-378.

Cevallos, M. A., Encarnacion, S., Leija, A., Mora, Y. \& Mora, J. (1996). Genetic and physiological characterization of a $R h i$ zobium etli mutant strain unable to synthesize poly-betahydroxybutyrate. J Bacteriol 178, 1646-1654.

Choi, J., Lee, S. Y. \& Han, K. (1998). Cloning of the Alcaligenes latus polyhydroxyalkanoate biosynthesis genes and use of these genes for enhanced production of poly(3-hydroxybutyrate) in Escherichia coli. Appl Environ Microbiol 64, 4897-4903.

Dieffenbach, C. W. \& Dveksler, G. S. (1995). PCR Primer: a Laboratory Manual. Cold Spring Harbor, NY: Cold Spring Harbor Laboratory.

Fukui, T. \& Doi, Y. (1997). Cloning and analysis of the poly(3hydroxy-co-3-hydroxyhexanoate) biosynthesis genes of Aeromonas caviae. J Bacteriol 179, 4821-4830.

Gomez, J. G. C., Rodrigues, M. F. A., Alli, R. C. P., Torres, B. B., Bueno Netto, C. L., Oliveira, M. S. \& Silva, L. F. da (1996). Evaluation of soil Gram-negative bacteria yielding polyhydroxyalkanoic acids from carbohydrates and propionic acid. Appl Microbiol Biotechnol 45, 785-791.

Henke, W., Herdel, K., Jung, K., Schnorr, D. \& Loening, S. A. (1997). Betaine improves the PCR amplification of GC-rich DNA sequences. Nucleic Acids Res 25, 3957-3958.

Huisman, G. W., Wonink, E., Meima, R., Kazemier, B., Terpstra, P. \& Witholt, B. (1991). Metabolism of poly(3-hydroxyalkanoates) (PHAs) by Pseudomonas oleovorans: identification and sequences of genes and function of the encoded proteins in the synthesis and degradation of PHA. J Biol Chem 266, 2191-2198.

Kranz, R. G., Gabbert, K. K. \& Madigan, M. T. (1997). Positive selection systems for discovery of novel polyester biosynthesis genes based on fatty acid detoxification. Appl Environ Microbiol 63, 3010-3013.

Madison, L. L. \& Huisman, F. W. (1999). Metabolic engineering of poly(3-hydroxyalkanoates): from DNA to plastic. Microbiol Mol Biol Rev 63, 21-53. 
Ostle, A. G. \& Holt, J. G. (1982). Nile blue A as a fluorescent stain for poly- $\beta$-hydroxybutyrate. Appl Environ Microbiol 44, 238-241.

Page, W. J. \& Manchak, J. (1995). The role of $\beta$-oxidation of short-chain alkanoates in polyhydroxyalkanoate copolymer synthesis in Azotobacter vinelandii UWD. Can J Microbiol 41 (Suppl. 1), 106-114.

Peoples, O. P. \& Sinskey, A. J. (1989). Poly-beta-hydroxybutyrate (PHB) biosynthesis in Alcaligenes eutrophus H16: identification and characterization of the PHB polymerase gene. J Biol Chem 264, 15298-15303.

Poirier, Y., Nawrath, C. \& Somerville, C. (1995). Production of polyhydroxyalkanoates, a family of biodegradable plastics and elastomers, in bacteria and plants. Bio/Technology 13, 142-150.

Ramsay, B. A., Lomaliza, K., Chavarie, C., Dube, B., Bataille, P. \& Ramsay, J. A. (1990). Production of poly-( $\beta$-hydroxybutyric-co- $\beta$ hydroxyvaleric) acids. Appl Environ Microbiol 56, 2093-2098.

Reed, K. C. \& Mann, D. A. (1985). Rapid transfer of DNA from agarose gels to nylon membranes. Nucleic Acid Res 13, 7207-7221.

Rehm, B. H. A. \& Steinbüchel, A. (1999). Biochemical and genetic analysis of PHA synthases and other proteins required for PHA synthesis. Int J Biol Macromol 25, 3-19.

Rehm, B. H. A., Krüger, N. \& Steinbüchel, A. (1998). A new metabolic link between fatty acid de novo synthesis and polyhydroxyalkanoic acid synthesis. J Biol Chem 273, 24044-24051.

Schembri, M. A., Bayly, R. C. \& Davies, J. K. (1994). Cloning and analysis of the polyhydroxyalkanoic acid synthase gene from an Acinetobacter sp.: evidence that the gene is both plasmid and chromosomally located. FEMS Microbiol Lett 118, 145-152.

Schlegel, H. G., Lafferty, R. \& Krauss, I. (1970). The isolation of mutants not accumulating poly- $\beta$-hydroxybutyric acid. Arch Mikrobiol 70, 283-294.
Spiekermann, P., Rehm, B. H. A., Kalscheuer, R., Baumeister, D. \& Steinbüchel, A. (1999). A sensitive, viable-colony staining method using nile red for direct screening of bacteria that accumulate polyhydroxyalkanoic acids and other lipid storage compounds. Arch Microbiol 171, 73-80.

Steinbüchel, A. \& Schlegel, H. F. (1991). Physiology and molecular genetics of poly(beta-hydroxy-alkanoic acid) synthesis in $\mathrm{Al}$ caligene eutrophus. Mol Microbiol 5, 535-542.

Sudesh, K., Fukui, T. \& Doi, Y. (1998). Genetic analysis of Comamonas acidovorans polyhydroxyalkanoate synthase and factors affecting the incorporation of 4-hydroxybutyrate monomer. Appl Environ Microbiol 64, 3437-3443.

Timm, A. \& Steinbüchel, A. (1992). Cloning and molecular analysis of the poly(3-hydroxyalkanoic acid) gene locus of Pseudomonas aeruginosa PAO1. Eur J Biochem 209, 15-30.

Tombolini, R., Povolo, S., Buson, A., Squartini, A. \& Nuti, M. P. (1995). Poly- $\beta$-hydroxybutyrate (PHB) biosynthetic genes in Rhizobium meliloti 41. Microbiology 141, 2553-2559.

Ueda, S., Yabutani, T., Maehara, A. \& Tamane, T. (1996). Molecular analysis of the poly(3-hydroxyalkanoate) synthase gene from a methylotrophic bacterium, Paracoccus denitrificans. J Bacteriol 178, 774-779.

Valentin, H. E. \& Steinbüchel, A. (1993). Cloning and characterization of the Methylobacterium extorquens polyhydroxyalkanoic-acid-synthase structural gene. Appl Microbiol Biotechnol 39, 309-317.

Zhang, X.-Y. \& Ehrlich, M. (1994). Detection and quantitation of low numbers of chromosomes containing $b c l-2$ oncogene translocations using semi-nested PCR. BioTechniques 16, 502-507.

Received 3 February 2000; revised 24 April 2000; accepted 12 May 2000. 